\title{
Short- and long-term effects of erythropoietin treatment on endothelial progenitor cell levels in patients with cardiorenal syndrome
}

\author{
Kim E Jie, ${ }^{1}$ Karien van der Putten, ${ }^{2,3}$ Marloes W T Bergevoet, ${ }^{1}$ Pieter A Doevendans, ${ }^{4}$ \\ Carlo A J M Gaillard, ${ }^{3,5}$ Branko Braam, ${ }^{6}$ Marianne C Verhaar ${ }^{1}$
}

- An additional table is published online only. To view this file please visit the journal online (http://heart.bmj.com)

1 Department of Nephrology and Hypertension, University Medical Center Utrecht, Utrecht, the Netherlands ${ }^{2}$ Department of Internal Medicine, Leiden University Medical Center, Leiden, the Netherlands

${ }^{3}$ Department of Internal Medicine, Meander Medical Center Amersfoort, Amersfoort, the Netherlands

${ }^{4}$ Department of Cardiology, University Medical Center Utrecht, Utrecht, the Netherlands

${ }^{5}$ Department of Nephrology, VU University Medical Center Amsterdam, the Netherlands ${ }^{6}$ Department of Medicine, Division of Nephrology and Immunology, University of Alberta, Edmonton, Canada

\section{Correspondence to}

Marianne C Verhaar, Department of Nephrology and Hypertension, University Medical Center Utrecht, Utrecht, the Netherlands; m.c.verhaar@umcutrecht.n

Accepted 28 September 2010 Published Online First 11 November 2010

\section{(2) UNLOCKA}

This paper is freely available online under the BMJ Journals unlocked scheme, see http:// heart.bmi.com/site/about/ unlocked.xhtml

\section{ABSTRACT}

Objective Patients with cardiorenal syndrome (CRS) have high cardiovascular morbidity. Endothelial progenitor cells (EPC) constitute an endogenous vascular repairsystem, protecting against atherosclerosis development. Erythropoietin (EPO) treatment may have beneficial effects by mobilizing EPC from the bonemarrow. Our objective is to determine EPC levels and effects of EPO therapy on EPC levels in CRS patients. Design Open-label randomized trial.

Setting Part of the EPOCARES-trial, conducted in Utrecht (Netherlands).

Patients Patients with CRS and anaemia and healthy controls were included.

Interventions Patients were randomized to receive EPO therapy $(50 \mathrm{lU} / \mathrm{kg} / \mathrm{wk})$ for 52 weeks or no EPO therapy. Main outcome measures $\mathrm{CD} 34^{+} \mathrm{KDR}^{+}-\mathrm{EPC}$, cultured EPC outgrowth and function at baseline, after 18 days and after 52 weeks.

Results Patients showed lower $\mathrm{CD} 34^{+} \mathrm{KDR}^{+}$-cell numbers compared to controls (6(12) vs. 19(19) cells/ $10^{5}$ granulocytes; $\left.p=0.010\right)$, despite increased levels of stromal cell-derived factor- $1 \alpha ;(3.1(0.8)$ vs $2.6(0.3)$ $\mathrm{ng} / \mathrm{ml} ; \mathrm{p}=0.001)$. EPC outgrowth and function were not different between patients and controls. EPC levels did not change after 18 days with or without EPO treatment. $\mathrm{CD} 4^{+} \mathrm{KDR}^{+}$-cells significantly declined after 52 weeks in the non-treated group $(p=0.028)$. Long-term EPO therapy did not significantly affect this reduction in $\mathrm{CD}^{+} 4^{+} \mathrm{KDR}^{+}$-EPC levels.

Conclusions CRS patients showed reduced CD34 ${ }^{+} \mathrm{KDR}^{+}$-EPC levels compared to controls, consistent with a reduced vascular regenerative potential and despite upregulated SDF-1 $\alpha$ levels. Over a one-year follow-up period a marked 68\% further reduction in EPC levels was observed in the patient group without EPO treatment. In spite of promising experimental studies, our longitudinal, randomized study did not show significant influence of either shortor long-term EPO therapy on reduced EPC levels in CRS patients.

\section{INTRODUCTION}

Patients with the cardiorenal syndrome (CRS) - ie, chronic heart failure (CHF) and chronic kidney disease (CKD), often accompanied by anaemiahave high cardiovascular morbidity and mortality. ${ }^{1}$ Endothelial dysfunction and impaired endothelial regenerative capacity play a key role in the pathogenesis of atherosclerosic cardiovascular disease (CVD). Bone marrow (BM) derived circulating endothelial progenitor cells (EPC) constitute an endogenous vascular repair system that may protect against atherosclerosis development. ${ }^{2}$ Reduced EPC availability or function may contribute to the pathogenesis of CVD.

Disease conditions with high cardiovascular risk, including end-stage renal disease, have been associated with reduced EPC levels and function. ${ }^{3}$ Others have not observed such inverse relations or even reported a positive relation between EPC number and vascular risk factors. ${ }^{4}$ In CHF, a negative correlation between cultured EPC and functional New York Heart Association (NYHA) class has been reported. ${ }^{5}$ However, others have found higher levels of EPC in mild CHF with increased levels of EPC mobilising factors, whereas EPC in severe disease were decreased, despite similar increases in stromal cell-derived factor- $1 \alpha$ (SDF-1 $\alpha$ ) and vascular endothelial growth factor (VEGF). ${ }^{67}$ This suggests a protective compensatory response to the vascular risk burden in mild CHF, but exhaustion or suppression of BM progenitor cells in advanced CHF. We hypothesised that in CRS, the combined presence of even mild stages of CHF, CKD and anaemia is associated with impaired levels of circulating EPC, due to accumulation of uremic toxins, decreased nitric oxide availability and increased inflammation.

Enhancing circulating EPC may enhance vascular protection and reduce the progression of CVD. Beneficial effects of erythropoietin (EPO) on the cardiovascular system have been suggested from animal experiments ${ }^{8}$ and small clinical studies in patients with $\mathrm{CKD}^{9}$ or $\mathrm{CHF}^{10}$ although these could not be confirmed in larger randomised trials. ${ }^{11}$ In patients with myocardial infarction, circulating $\mathrm{CD}^{+} 4^{+}$haematopoietic stem cells (HSC) increased after single high-dose EPO injection. $^{8}$ Regular dose EPO treatment increased EPC levels in advanced $\mathrm{CKD}^{12}$ and improved EPC function in CHF patients in the longer term. ${ }^{13}$ No randomised controlled studies are available on EPC and regular EPO dose effects in patients with CRS. We hypothesised that EPO treatment can improve EPC levels in CRS patients, which may be related to a reduction in cardiovascular risk.

We assessed circulating EPC levels and EPC outgrowth number and function in CRS patients compared to healthy controls, and evaluated whether short-term (18 days) and long-term (52 weeks) EPO therapy improved EPC number and function in patients with CRS. 


\section{METHODS}

\section{Study subjects}

We studied a subgroup of CRS patients from the EpoCaReS trial (ClinicalTrials.gov, NCT00356733), and healthy controls of comparable age and gender. A detailed description with inclusion and exclusion criteria of the study has previously been published. ${ }^{14}$ The protocol was approved by the medical ethics committee and all patients gave informed consent. Procedures were in accordance with the Helsinki Declaration.

Patients with mild anaemia (women: 6.4-7.4 mmol/1; men: 6.4-7.8 mmol/1), moderate CKD (estimated creatinine clearance 20-70 ml/min, Cockcroft-Gault formula) and CHF (functional NYHA class II-IV, based on symptoms, signs and objective abnormality on echocardiography, ${ }^{15}$ reduced ejection fraction $(<50 \%)$ or left ventricular end-diastolic volume index $<97 \mathrm{ml} / \mathrm{m}^{2}$ with evidence of diastolic left ventricular dysfunction ${ }^{16}$ ) were included.

\section{Study design}

EPC levels and function were compared between 45 CRS patients at baseline and 20 healthy controls. The effects of EPO treatment were evaluated in an open-label, randomised design. Patients received EPO treatment $(50 \mathrm{IU} / \mathrm{kg} /$ week; Neorecormon, Roche Pharmaceuticals, Woerden, Netherlands) or standard treatment without EPO for one year. Short-term effects of EPO $(\mathrm{n}=30)$ versus no EPO $(\mathrm{n}=15)$ were evaluated after 18 days (3 days after third EPO injection), when EPO treatment was not yet expected to result in a haematopoietic response. Long-term (52 week) effects of EPO were assessed in a subgroup of EPOtreated patients, who were allowed to increase haemoglobin $(\mathrm{Hb})$ levels up to $8.5 \mathrm{mmol} / 1$ for men and $8.3 \mathrm{mmol} / 1$ for women $(\mathrm{n}=13)$, and a non EPO-treated group $(\mathrm{n}=13)$.

\section{Plasma measurements}

Serum EPO levels were measured by sandwich chemiluminescent immunoassay (IMMULITE 2000 platform, Siemens Healthcare Diagnostics, Breda, Netherlands). Endothelial dysfunction, EPC mobilising factors and inflammation markers were measured using ELISA (E-selectin, vascular cell adhesion molecule-1 (VCAM-1), interleukin (IL)-6, VEGF, SDF-1 $\alpha$ (R\&D Systems, Minneapolis, Minnesota, USA) and thrombomodulin (Diaclone, Stamford, Connecticut, USA)) or multiplex immunoassay $^{17}$ (intercellular adhesion molecule-1 (ICAM-1) and monocyte chemotactic protein-1 (MCP-1) (Bio-Rad Laboratories, Hercules, California, USA)). High sensitivity $C$ reactive protein (hsCRP) was determined by particle-enhanced immunonephelometry (standard Cardio-Phase hsCRP for BNII, Dade Behring Holding, Liederbach, Germany). N-terminal prohormone of brain natriuretic peptide (NT-proBNP) was measured using electrochemiluminescense immunoassay (Cobas CA6000, Roche, Mannheim, Germany). Samples were measured in duplicate and averaged for analysis.

\section{Circulating EPC levels}

Circulating EPC were defined as cells positive for haematopoietic stem cell marker CD34 and endothelial marker kinase insert domain receptor (KDR; ie, VEGF receptor-2). This $\mathrm{CD}^{+} 4^{+}$ $\mathrm{KDR}^{+}$-EPC has previously shown clinical importance by predicting cardiovascular events and death in cardiovascular risk populations. ${ }^{18} 19$ Blood $(100 \mu \mathrm{l})$ was incubated with anti-CD34FITC (BD Pharmingen, California, USA), anti-KDR-PE (R\&D Systems) and anti-CD45-PE-Cy7 (BD Pharmingen) antibodies for $45 \mathrm{~min}$. Erythrocytes were lysed and analysed by flow cytometry (Beckman Coulter, California, USA). Circulating
HSC and EPC were identified as $\mathrm{CD}_{3} 4^{+}$and $\mathrm{CD}_{3} 4^{+} \mathrm{KDR}^{+}$cells in the lymphocyte region of the forward/sideward scatter plot. Cell numbers were quantified relative to $10^{5}$ granulocytes, identified as $\mathrm{CD} 45^{+}$cells with a typical granulocyte distribution. Measurements were performed in duplicate and results were averaged. Isotype-stained samples served as negative controls.

\section{Outgrowth of EPC in culture}

EPC outgrowth from mononuclear cells (MNC) was assessed as described previously. ${ }^{3}$ In brief, MNC were isolated from blood using Ficoll density gradient separation (Histopaque 1077, Sigma, St Louis, Missouri, USA). To evaluate EPC outgrowth in culture, $10^{7} \mathrm{MNC} /$ well were seeded on a human fibronectin (Sigma) coated 6-well plate in EGM-2 (Cambrex, Baltimore, Maryland, USA), supplemented with accompanying aliquots, $20 \%$ fetal calf serum (Invitrogen, Carlsbad, California, USA), $100 \mathrm{ng} / \mathrm{ml}$ recombinant VEGF-165 (R\&D Systems) and antibiotics. Medium was changed after 4 days to wash non-adherent cells away. After 7 days, cultured EPC in selected wells were placed on serum free medium (EBM-2 with hEGF, hydrocortisone, GA-1000, $\mathrm{R}^{3}$-IGF-1, ascorbic acid, heparin and antibiotics) overnight. Conditioned medium was stored for functional experiments and cultured EPC were detached by trypsin and cell scraping, and automatically counted using a haemocytometer.

\section{In vitro scratch wound assay}

The potential of EPC outgrowth to excrete paracrine factors that stimulate endothelial cell migration was assessed by in vitro scratch wound assay. ${ }^{20}$ In brief, EPC outgrowth medium was placed on a mechanically scratched confluent human microvascular endothelial cell layer. After $6 \mathrm{~h}$, the extent of scratch closure relative to the starting width was compared between study groups using light photography. Each sample was measured in two separate wells and two picture fields per well were examined. Results were averaged for data analysis.

\section{Statistical analysis}

Data analysis was performed using SPSS V.15.0 for Windows. Data distribution was tested by the Kolmogorov-Smirnov test. Data are expressed as mean $\pm \mathrm{SD}$ for parametric data and as median (IOR) for non-parametric data. Differences between groups were analysed using Student's t test or the Mann-Whitney test. Fisher's exact test was used to analyse whether proportions of categories varied by group. Multiple group comparisons were performed using ANOVA with LSD post-hoc testing for which non-parametric data were log-transformed. Correlations were measured by Pearson's or Spearman's correlation coefficient where appropriate. Multivariate determinants of log-transformed progenitor cell counts were identified by stepwise multiple linear regression analysis. A value of $p<0.05$ was considered statistically significant.

\section{RESULTS}

\section{Baseline characteristics}

Table 1 summarises baseline characteristics. Patients were mildly anaemic, had reduced creatinine clearance, lower diastolic blood pressure and reduced ejection fraction. CRS patients demonstrated increased hsCRP levels and higher levels of markers for endothelial dysfunction compared to healthy controls.

\section{Haemoglobin levels during the study}

Short-term EPO did not significantly change Hb levels (7.5 (1.2) vs $7.3(1.0) \mathrm{mmol} / \mathrm{l} ; \mathrm{p}=0.061)$, but significantly increased reticulocyte count $\left(0.066 \pm 0.004\right.$ vs $\left.0.045 \pm 0.003 \times 10^{12} / 1 ; p<0.001\right)$ 
Table 1 Baseline characteristics of study population

\begin{tabular}{|c|c|c|c|}
\hline & $\begin{array}{l}\text { Healthy } \\
\text { controls }\end{array}$ & $\begin{array}{l}\text { CRS, } \\
\text { no EPO }\end{array}$ & $\begin{array}{l}\text { CRS, } \\
\text { EPO }\end{array}$ \\
\hline Age, years & $72.0(5.9)$ & $74(14)$ & $76(11)$ \\
\hline Male sex, n (\%) & $15(75)$ & $11(73)$ & $20(67)$ \\
\hline Body mass index, $\mathrm{kg} / \mathrm{m}^{2}$ & $23.3 \pm 2.3$ & $27 \pm 4^{*}$ & $26 \pm 4^{*}$ \\
\hline Systolic blood pressure, $\mathrm{mm} \mathrm{Hg}$ & $127 \pm 20$ & $124 \pm 21$ & $125 \pm 18$ \\
\hline Diastolic blood pressure, $\mathrm{mm} \mathrm{Hg}$ & $79 \pm 9$ & $67 \pm 10^{*}$ & $65 \pm 9 *$ \\
\hline Plasma total cholesterol, $\mathrm{mmol} / \mathrm{l}$ & $4.8 \pm 0.9$ & $4.5 \pm 1.2$ & $4.0 \pm 1.1^{*}$ \\
\hline HDL cholesterol, mmol/l & $1.4 \pm 0.4$ & $1.0 \pm 0.2^{*}$ & $1.3 \pm 0.3$ \\
\hline LDL cholesterol, mmol/l & $3.1 \pm 0.7$ & $2.6 \pm 0.8$ & $2.1 \pm 0.9^{*}$ \\
\hline Haemoglobin, mmol/l & $8.6(0.7)$ & $7.4(0.6)^{*}$ & $7.3(1.1)^{*}$ \\
\hline Serum EPO level, IU/I & NA & $11.5 \pm 6.8$ & $11.9 \pm 6.0$ \\
\hline $\begin{array}{l}\text { Estimated creatinine clearance, } \\
\mathrm{ml} / \mathrm{min}\end{array}$ & $66(22)$ & $30(31)^{*}$ & $31(25)^{*}$ \\
\hline Serum urea, mmol/l & $5.1(2.3)$ & $12.2(9.5)^{*}$ & $16.0(10.6)^{*}$ \\
\hline NT-proBNP, pg/ml & NA & $1680(2132)$ & $2064(3155)$ \\
\hline Ejection fraction, \% & NA & $46 \pm 13$ & $43 \pm 14$ \\
\hline $\begin{array}{l}\text { Aetiology CHF, } \mathrm{n} \text { ischaemic/ } \\
\text { hypertensive/valvular/other }\end{array}$ & - & $11 / 2 / 2 / 0$ & $17 / 4 / 3 / 6$ \\
\hline hsCRP, mg/l & $1.04(2.53)$ & $4.59(7.90)$ & $5.77(9.14)$ \\
\hline Diabetes mellitus, $n(\%)$ & 0 & $4(27)$ & $10(33)$ \\
\hline Smoker, n (\%) & $6(30)$ & $3(20)$ & $2(7)$ \\
\hline \multicolumn{4}{|l|}{ Medication, n (\%) } \\
\hline Statin & 0 & $10(67)$ & $21(70)$ \\
\hline Angiotensin blocker & 0 & $14(93)$ & $27(90)$ \\
\hline Beta blocker & 0 & $9(60)$ & $20(67)$ \\
\hline Aldactone & 0 & $4(27)$ & $8(27)$ \\
\hline \multicolumn{4}{|l|}{ Endothelial dysfunction parameters } \\
\hline ICAM-1, ng/ml & $213(56)$ & $284(124)$ & $336(226)^{*}$ \\
\hline VCAM-1, ng/ml & $23.3(4.5)$ & $97(80)^{*}$ & $103(56)^{*}$ \\
\hline Thrombomodulin, ng/ml & $<0.01(0.15)$ & $1.1(1.2)^{*}$ & $0.9(1.7)^{*}$ \\
\hline eSelectin, $\mathrm{ng} / \mathrm{ml}$ & $3.32 \pm 0.81$ & $4.22 \pm 1.76$ & $4.13 \pm 1.23$ \\
\hline
\end{tabular}

compared to baseline. Long-term EPO significantly increased $\mathrm{Hb}$ levels compared to baseline (8.4 (0.8) vs 6.9 (0.8) $\mathrm{mmol} / \mathrm{l}$; $\mathrm{p}=0.012)$. Patients not treated with EPO remained anaemic at all time-points (7.4 (0.4) baseline, 7.2 (0.8) 18 days, 7.4 (0.9) mmol/1 52 week; p-value not significant between time-points).

\section{Circulating EPC levels are reduced in CRS patients compared to healthy controls}

$\mathrm{CD} 4^{+} \mathrm{KDR}^{+}$-EPC were $68 \%$ lower in CRS patients at baseline compared to controls (figure 1A). CRS patients tended to have lower CD34 ${ }^{+}$-HSC (38\% reduction; figure $\left.1 \mathrm{~B}\right)$. No differences were found in EPC outgrowth (figure 1C). In a scratch wound assay, we observed no significant difference between conditioned medium from EPC outgrowth cultures from CRS patients and controls for their capacity to stimulate endothelial cell migration (figure 1D).

Univariate analysis revealed lower $\mathrm{CD} 34^{+} \mathrm{KDR}^{+}$-EPC levels in subjects with advanced age $(r=-0.352 ; p=0.007)$, lower $\mathrm{Hb}$ $(r=0.362 ; p=0.005)$ and estimated creatinine clearance $(r=0.328$; $\mathrm{p}=0.012)$, and higher IL-6 levels $(\mathrm{r}=-0.302 ; \mathrm{p}=0.044)$ (supplementary table). CD34 ${ }^{+}$-HSC were also negatively correlated with age $(r=-0.273 ; p=0.038)$ and IL-6 levels $(r=-0.454 ; p=0.002)$ and tended to decrease in patients with lower estimated creatinine clearance $(\mathrm{r}=0.241 ; \mathrm{p}=0.068)$ and higher serum urea $(\mathrm{r}=-0.258$; $\mathrm{p}=0.053)$. CD $34^{+}$-HSC were increased in patients with higher plasma low density lipoprotein (LDL) $(r=0.285 ; p=0.035)$. After multivariate regression analysis of log-transformed $\mathrm{CD} 4^{+} \mathrm{KDR}^{+}$-EPC levels for age, $\mathrm{Hb}$, estimated creatinine clearance and IL-6, only $\mathrm{Hb}$ remained an independent predictor of circulating EPC levels ( $\beta=0.323 ; 95 \%$ CI 0.021 to $0.538 ; p=0.034$ ). Only IL-6 ( $\beta=-0.443 ; 95 \% \mathrm{CI}-0.135$ to $-0.029 ; \mathrm{p}=0.003)$ was an independent predictor of log-transformed CD $34^{+}$-HSC in multivariate regression analysis for age, IL-6 and plasma LDL levels.

No correlations were found for $\mathrm{CD}_{3} 4^{+}$- and $\mathrm{CD}_{4}{ }^{+} \mathrm{KDR}^{+}-$ cells with serum EPO levels. Presence of diabetes, statin use or $\beta$-blockade treatment were not associated with circulating
Figure 1 Progenitor cell levels and function in patients with cardiorenal syndrome (CRS) compared to healthy controls. Comparison of circulating $\mathrm{CD}_{4}{ }^{+} \mathrm{KDR}^{+}$-cell levels (A), CD34 ${ }^{+}$-cell levels $(B)$, cultured endothelial progenitor cell (EPC) number (C) and function as determined by scratch wound analysis (D) between CRS patients $(n=45)$ and healthy controls $(n=20)$. NC, negative control.
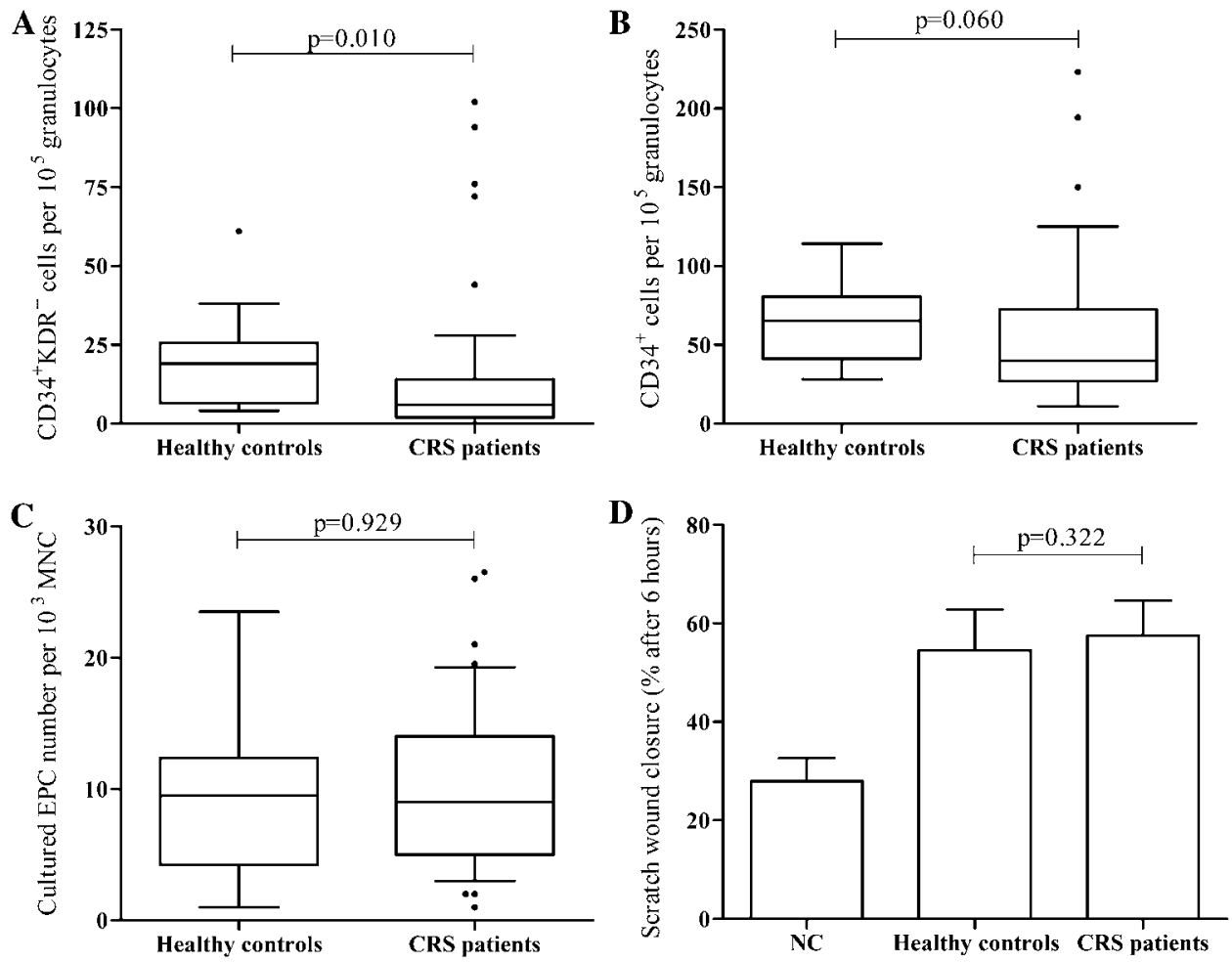
progenitor cell counts. CD34 ${ }^{+}$-cell levels tended to correlate negatively with all levels of measured endothelial dysfunction parameters at baseline. Reduced $\mathrm{CD} 34^{+} \mathrm{KDR}^{+}$-cell levels were also associated with increased VCAM-1 levels, but not with other endothelial dysfunction measures (supplementary table). EPC outgrowth level and function were not associated with any of the markers.

SDF- $1 \alpha$ levels were significantly enhanced in CRS patients versus controls (3.1 (0.8) vs $2.6(0.3) \mathrm{pg} / \mathrm{ml} ; \mathrm{p}=0.001)$. SDF-1 $\alpha$ levels correlated with estimated creatinine clearance $(\mathrm{r}=-0.361$; $p=0.004)$, serum urea $(r=0.527 ; p<0.001), \mathrm{Hb} \quad(r=-0.276$; $\mathrm{p}=0.03)$ and NT-proBNP $(\mathrm{r}=0.503 ; \mathrm{p}=0.001)$, but not with ejection fraction $(r=-0.190 ; p=0.307)$. SDF- $1 \alpha$ levels increased with deterioration of endothelial dysfunction measured by ICAM-1 ( $r=0.437 ; p=0.002)$ VCAM-1 $(r=0.553 ; p<0.001)$ and thrombomodulin $(\mathrm{r}=0.494 ; \mathrm{p}<0.001)$, but not with eSelectin $(r=0.203 ; p=0.162)$. ICAM-1 $(\beta=0.313 ; 95 \%$ CI 0.000 to $0.002 ; p=0.041)$ and VCAM-1 ( $\beta=0.441 ; 95 \%$ CI 1.888 to 9.813; $p=0.005)$ remained independent predictors of SDF- $1 \alpha$ in multivariate regression analysis for significant univariate determinants.

We observed no relation between levels of circulating $\mathrm{CD}^{+} 4^{+} \mathrm{KDR}^{+}$-cells and SDF-1 $\alpha$ levels in the total patient population $(r=0.127 ; p=0.352)$. However, SDF- $1 \alpha$ was correlated with $\mathrm{CD}_{3}{ }^{+} \mathrm{KDR}^{+}$-cells in patients with milder $\mathrm{CHF}$ indicated by low levels (below median) of NT-proBNP $(r=0.469$; $\mathrm{p}=0.05)$ or high (above median) ejection fraction $(r=0.651$; $p=0.022$ ). Correlations were absent or even reversed in more severe CHF ( $r=0.104 ; p=0.661$ in patients with NT-proBNP levels above median, and $r=-0.461 ; p=0.083$ in patients with ejection fraction below median). SDF- $1 \alpha$ and $\mathrm{CD}^{+} 4^{+} \mathrm{KDR}^{+}$-cell correlations were absent in patients above as well as below median estimated creatinine clearance. Levels of VEGF were not different between CRS patients and controls (24.8 (16.4) vs 22.5 (7.1) $\mathrm{pg} / \mathrm{ml} ; \mathrm{p}=0.212$ ).

Short-term EPO treatment has no effect on EPC in CRS patients Short-term (18 days) EPO had no effect on levels of CD34 ${ }^{+}$or $\mathrm{CD} 34^{+} \mathrm{KDR}^{+}$-cells, EPC outgrowth and migratory function as compared to baseline (figure 2). Progenitor cell levels and function also did not significantly change in the non EPO-treated group as compared to baseline. No significant differences in $\mathrm{CD}_{3} 4^{+}$- and $\mathrm{CD} 34^{+} \mathrm{KDR}^{+}$-cells, and EPC outgrowth and function were observed between the EPO-treated and non EPO-treated group.

\section{Long-term EPO treatment prevents a decline in EPC in CRS patients}

Long-term (52 weeks) EPO did not alter $\mathrm{CD} 34^{+} \mathrm{KDR}^{+}$-EPC, CD $34^{+}$-HSC levels, EPC outgrowth or function compared to baseline. In patients not treated with EPO a significant decline in $\mathrm{CD} 34^{+} \mathrm{KDR}^{+}$-EPC was found after 52 weeks (figure $3 \mathrm{~A}$ ). $\mathrm{CD} 34^{+} \mathrm{KDR}^{+}$-EPC tended to be lower in patients without EPO therapy after 52 weeks compared to those who received EPO therapy $(p=0.077)$, whereas levels were not different between the groups at baseline $(p=0.437)$. No differences in CD34 ${ }^{+}$-HSC, EPC outgrowth and function were observed in the group without EPO treatment after 52 weeks as compared to baseline (figure $3 \mathrm{~B}-\mathrm{D}$ ).

\section{DISCUSSION}

The present data show that patients with CRS and anaemia who receive standard medication have reduced levels of circulating $\mathrm{CD} 34^{+} \mathrm{KDR}^{+}$-EPC, despite increased levels of progenitor cell mobilising factor SDF-1 $\alpha$. We observed no effect of shortterm, 18 days EPO therapy on EPC levels. In cardiorenal patients not treated with EPO, we observed a marked reduction in $\mathrm{CD} 4^{+} \mathrm{KDR}^{+}$-EPC levels after one year compared to baseline. Long-term, 52 weeks EPO therapy did not significantly affect this reduction in $\mathrm{CD} 34^{+} \mathrm{KDR}^{+}$-EPC levels.

Our study is the first to report reduced circulating progenitor cells in patients with CRS. Studies on circulating EPC in patients with CHF report variable results. ${ }^{6} 72122$ We observed that in the presence of $\mathrm{CHF}, \mathrm{CKD}$ and anaemia, $\mathrm{CD}_{3} 4^{+} \mathrm{KDR}^{+}$cell levels were decreased independent of cardiac disease severity, as assessed by ejection fraction or NT-proBNP levels. Plasma levels of NT-proBNP may be influenced by renal dysfunction, but remain a powerful reflection of cardiac status. ${ }^{23}$ At tissue level EPC recruitment depends on ischaemia or endothelial injury induced up-regulation of SDF-1 $\alpha$. In our study, SDF-1 $\alpha$ levels correlated with renal function, heart function and endothelial dysfunction markers, indicating that signals for
Figure 2 Short-term effects of erythropoietin (EPO) treatment on circulating endothelial progenitor cell (EPC) in patients with cardiorenal syndrome (CRS). Comparison of circulating CD34+KDR +-cell levels (A), CD34+-cell levels (B), cultured EPC number $(C)$ and function as determined by scratch wound analysis (D) between CRS patients treated with EPO for 18 days ( $n=30$, open bars) and non-EPO treated patients $(n=15$, filled bars).
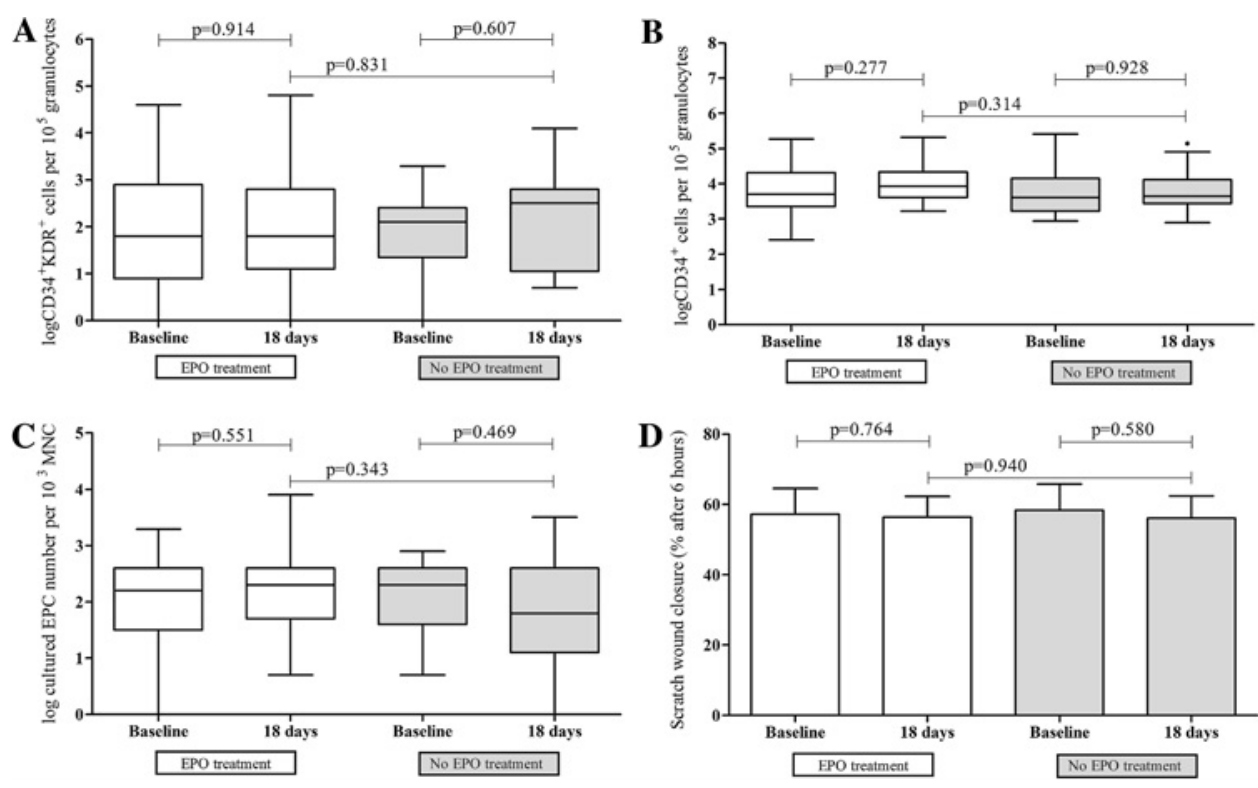
Figure 3 Long-term effects of erythropoietin (EPO) treatment on circulating endothelial progenitor cell (EPC) in patients with cardiorenal syndrome (CRS). Comparison of circulating CD34+KDR+-cell levels (A), CD34+-cell levels (B), cultured EPC number $(C)$ and function as determined by scratch wound analysis (D) between CRS patients treated with EPO for 52 weeks ( $n=13$, open bars) and non-EPO treated patients $(n=13$, filled bars).
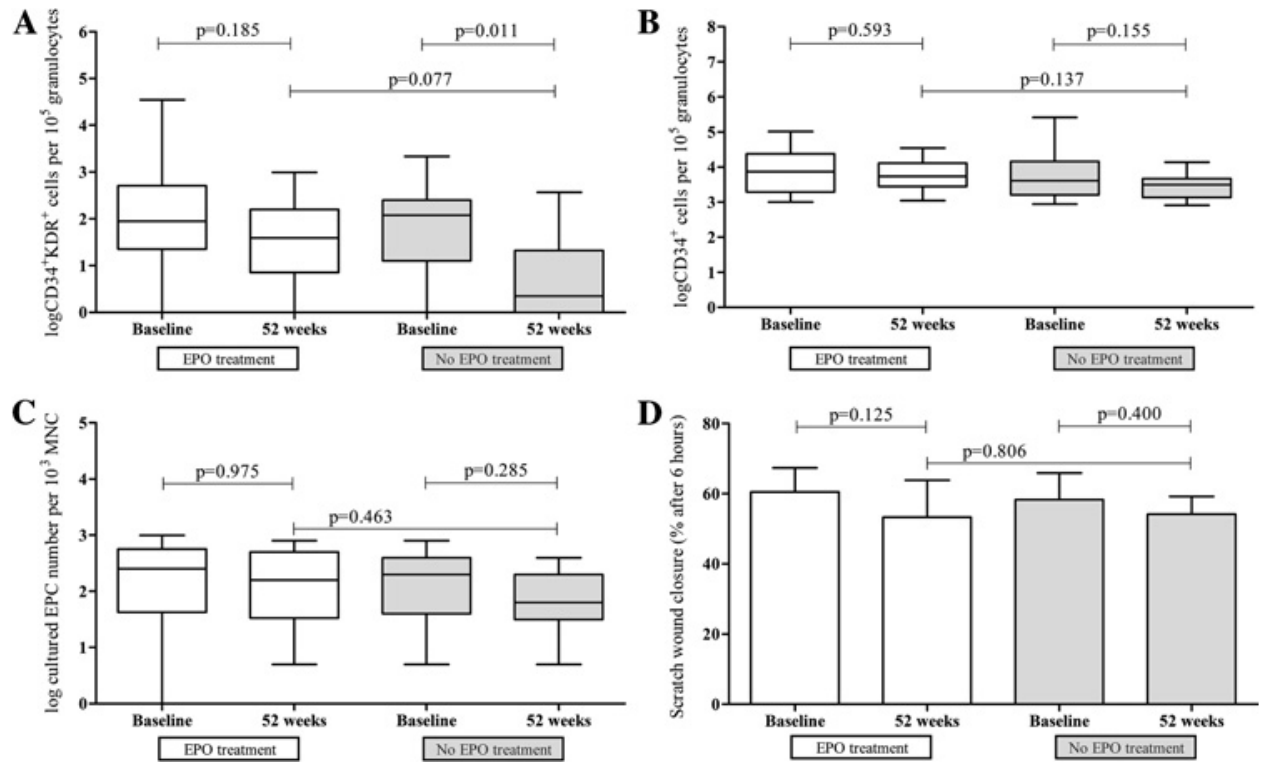

progenitor cell mobilisation are intact. However, this did not result in an efficient EPC increase in CRS. This may be explained by impaired EPC production due to uraemia and other cardiovascular risk factors and/or increased homing to injured endothelium. In agreement with previous results, ${ }^{7}$ in CRS patients with mild CHF, increased SDF-1 $\alpha$ levels were associated with higher $\mathrm{CD} 34^{+} \mathrm{KDR}^{+}$-EPC levels, suggesting that in milder $\mathrm{CHF}$ stages SDF- $1 \alpha$ can lead to EPC mobilisation. In contrast, in severe CHF the association between SDF-1 $\alpha$ and EPC levels disappeared or even reversed, suggesting an impaired EPC mobilising response to SDF- $1 \alpha$ in this stage. This is consistent with the biphasic response reported in severe $\mathrm{CHF}^{6}{ }^{7}$ and may relate to exhaustion of haematopoietic progenitors at the BM level or inflammatory factors exerting BM suppression in advanced $\mathrm{CHF}^{7}$ Indeed, our data show a significant inverse relation between IL- 6 levels and $\mathrm{CD} 34^{+}$-HSC numbers. Inflammatory cytokines are known to exert a suppressive effect on erythropoiesis. Consistently, in our patients with mild anaemia we observed lower $\mathrm{Hb}$ levels when hsCRP levels were higher. We observed no correlations between serum EPO levels and either $\mathrm{Hb}$ levels or endothelial progenitor cell counts. Interestingly, $\mathrm{CD}_{34}{ }^{+} \mathrm{KDR}^{+}$-EPC levels correlated positively with $\mathrm{Hb}$ levels, suggesting a common BM suppressive effect on both EPC production or mobilisation and erythropoiesis.

In our study short-term EPO administration did not influence HSC or EPC levels. This contrasts with previous reports in CKD or post-myocardial infarction patients. ${ }^{8} 12$ In part this discrepancy may be explained by differences in EPO dosage, as EPC response to EPO has been shown to be dose-dependent. ${ }^{24}$ Since the potential clinical problems caused by long-term EPO are presumably dose-related, ${ }^{25}$ our patients received a relatively low, currently recommended, EPO dosage (50 IU/kg/week). This was sufficient to enhance reticulocyte levels. It could be that our CRS patients were not able to increase EPC levels in response to EPO due to exhaustion or suppression of these progenitors at the BM level. ${ }^{26}$ In line with this hyporesponsiveness of EPC on EPO, we observed no relations between serum EPO and EPC levels, whereas endogenous EPO levels were reported to be positively associated with EPC levels in $\mathrm{CHF}^{27}$ or $\mathrm{CKD} .^{28}$

To our knowledge, no previous randomised trials have reported on one-year follow-up of EPC or HSC levels in a high CVD risk population. In patients not treated with EPO, we observed a $68 \%$ reduction in $\mathrm{CD} 34^{+} \mathrm{KDR}^{+}$-EPC levels after one year compared to baseline, whereas HSC levels remained unchanged compared to baseline. This discrepancy may be related to the fact that CRS is associated with impaired NO availability, and that $\mathrm{NO}$ and the NO producing enzyme eNOS are essential for EPC mobilisation. ${ }^{29}$ Our finding that EPC reduced over time whereas HSC were not affected seems consistent with the observation that $\mathrm{NO}$ supported mobilisation of EPC but not of HSC in a mouse model. ${ }^{30}$ Long-term EPO treatment showed a minor and non-significant effect on preserving EPC levels over one year. One previous study reported no difference in EPC levels between EPO and non-EPO treated CHF patients after 2.5 years follow-up. However, this observation may be confounded by the cross-sectional study design and retrospective matching of the control group. ${ }^{13}$

In contrast to circulating $\mathrm{CD} 34^{+} \mathrm{KDR}^{+}-\mathrm{EPC}, \mathrm{EPC}$ outgrowth and function were not different between CRS patients and controls. It could be that CRS affects mainly the 'true' progenitor cells in the haematopoietic/endothelial lineage as it affects progenitors in the erythropoietic lineage in $\mathrm{BM} . \mathrm{CD}^{+} 4^{+} \mathrm{KDR}^{+}$EPC represent a defined subset of true BM-derived progenitor cells with the ability for clonal expansion into endothelial cell colonies from single cells. ${ }^{31}$ Cultured EPC are mostly derived from CD34-negative cells, and can adopt an endothelial phenotype after culture, but are not able to clonally expand. Earlier studies reported decreased EPC outgrowth and colony forming units in $\mathrm{CHF}^{5726}$ or CKD. ${ }^{32}$ Besides study population differences, differences in culture method may contribute to the observed discordances. 571332 However, our methodology is the same as in previous studies in which we found reduced $\mathrm{CD} 34^{+} \mathrm{KDR}^{+}$-EPC and EPC outgrowth in patients with $\mathrm{CKD}^{20}$ and ESRD, ${ }^{3}$ and comparable to methods used in articles reporting reduced cultured $\mathrm{EPC}$ in $\mathrm{CHF}^{26}$ and $\mathrm{CKD}{ }^{33}$

In conclusion, CRS patients showed reduced $\mathrm{CD} 34^{+} \mathrm{KDR}^{+}$EPC levels, consistent with a reduced vascular regenerative potential and despite increased SDF- $1 \alpha$ levels. Over a one-year follow-up period a marked $68 \%$ further reduction in EPC levels was observed in the patient group without EPO treatment. In spite of promising experimental studies, our longitudinal, randomised study did not show significant influence of either shortor long-term EPO therapy on reduced EPC levels in CRS patients. 
Acknowledgements We would like to thank Adry Diepenbroek and Mireille Emans from the Meander Medical Center Amersfoort, the Netherlands, for their excellent patient care assistance.

Funding This work was supported by the Netherlands Heart Foundation (grant number 2005B192); an unrestricted grant from Roche; the Netherlands Organisation for Scientific Research (Vidi grant number 016.096.359 to MCV); and the University Medical Center Utrecht (MD/PhD fellowship to KEJ).

Competing interests None declared.

Ethics approval The protocol was approved by the medical ethics committee and all patients gave informed consent. Procedures were in accordance with the Helsinki Declaration.

Provenance and peer review Not commissioned; externally peer reviewed.

\section{REFERENCES}

1. Smith GL, Lichtman JH, Bracken MB, et al. Renal impairment and outcomes in heart failure: systematic review and meta-analysis. J Am Coll Cardiol 2006:47:1987-96

2. Asahara T, Murohara T, Sullivan A, et al. Isolation of putative progenitor endothelial cells for angiogenesis. Science 1997;275:964-7.

3. Westerweel PE, Hoefer IE, Blankestijn PJ, et al. End-stage renal disease causes an imbalance between endothelial and smooth muscle progenitor cells. Am J Physiol Renal Physiol 2007;292:F1132-40.

4. Xiao 0, Kiechl S, Patel S, et al. Endothelial progenitor cells, cardiovascular risk factors, cytokine levels and atherosclerosis-results from a large population-based study. PLOS One 2007;2:e975.

5. Michowitz Y, Goldstein E, Wexler D, et al. Circulating endothelial progenitor cells and clinical outcome in patients with congestive heart failure. Heart 2007;93:1046-50.

6. Nonaka-Sarukawa M, Yamamoto $\mathrm{K}$, Aoki $\mathrm{H}$, et al. Circulating endothelial progenitor cells in congestive heart failure. Int J Cardiol 2007;119:344-8.

7. Valgimigli M, Rigolin GM, Fucili A, et al. CD34+ and endothelial progenitor cells in patients with various degrees of congestive heart failure. Circulation 2004;110:1209-12.

8. Lipsic $\mathbf{E}$, van der Meer $\mathrm{P}$, Voors $\mathrm{AA}$, et al. A single bolus of a long-acting erythropoietin analogue darbepoetin alfa in patients with acute myocardial infarction: a randomized feasibility and safety study. Cardiovasc Drugs Ther 2006:20:135-41.

9. Hayashi T, Suzuki A, Shoji T, et al. Cardiovascular effect of normalizing the hematocrit level during erythropoietin therapy in predialysis patients with chronic renal failure. Am J Kidney Dis 2000;35:250-6.

10. Silverberg DS, Wexler D, Sheps D, et al. The effect of correction of mild anemia in severe, resistant congestive heart failure using subcutaneous erythropoietin and intravenous iron: a randomized controlled study. J Am Coll Cardiol 2001;37:1775-80.

11. Roger SD, McMahon LP, Clarkson A, et al. Effects of early and late intervention with epoetin alpha on left ventricular mass among patients with chronic kidney disease (stage 3 or 4): results of a randomized clinical trial. J Am Soc Nephrol 2004:15:148-56.

12. Bahlmann FH, De Groot K, Spandau JM, et al. Erythropoietin regulates endothelial progenitor cells. Blood 2004;103:921-6.

13. George J, Goldstein E, Abashidze A, et al. Erythropoietin promotes endothelia progenitor cell proliferative and adhesive properties in a PI 3-kinase-dependent manner. Cardiovasc Res 2005;68:299-306.
14. Van der Putten K, Jie KE, Emans ME, et al. Erythropoietin treatment in patients with combined heart and renal failure: objectives and design of the EPOCARES study. J Nephrol 2010;23:363-8.

15. Dickstein K, Cohen-Solal A, Filippatos G, et al. ESC Guidelines for the diagnosis and treatment of acute and chronic heart failure 2008: the Task Force for the Diagnosis and Treatment of Acute and Chronic Heart Failure 2008 of the European Society of Cardiology. Developed in collaboration with the Heart Failure Association of the ESC (HFA) and endorsed by the European Society of Intensive Care Medicine (ESICM). Eur Heart J 2008:29:2388-442.

16. Paulus WJ, Tschope C, Sanderson JE, et al. How to diagnose diastolic heart failure: a consensus statement on the diagnosis of heart failure with normal left ventricula ejection fraction by the Heart Failure and Echocardiography Associations of the European Society of Cardiology. Eur Heart J 2007;28:2539-50.

17. de Jager W, Prakken BJ, Bijlsma JW, et al. Improved multiplex immunoassay performance in human plasma and synovial fluid following removal of interfering heterophilic antibodies. J Immunol Methods 2005;300:124-35.

18. Schmidt-Lucke C, Rossig L, Fichtlscherer S, et al. Reduced number of circulating endothelial progenitor cells predicts future cardiovascular events: proof of concept for the clinical importance of endogenous vascular repair. Circulation 2005:111:2981-7.

19. Werner N, Kosiol S, Schiegl T, et al. Circulating endothelial progenitor cells and cardiovascular outcomes. N Engl J Med 2005;353:999-1007.

20. Jie KE, Zaikova MA, Bergevoet MW, et al. Progenitor cells and vascular function are impaired in patients with chronic kidney disease. Nephrol Dial Transplant 2010;25:1875-82

21. Fritzenwanger $\mathbf{M}$, Lorenz $F$, Jung $\mathbf{C}$, et al. Differential number of CD34+, CD133+ and CD34+/CD133 + cells in peripheral blood of patients with congestive heart failure. Eur J Med Res 2009:14:113-17.

22. Theiss HD, David R, Engelmann MG, et al. Circulation of CD34+ progenitor cell populations in patients with idiopathic dilated and ischaemic cardiomyopathy (DCM and ICM). Eur Heart J 2007:28:1258-64.

23. Palmer SC, Richards AM. Does renal clearance differ between the B-type natriuretic peptides (BNP versus NT-proBNP)? J Am Coll Cardiol 2009;53:891-2.

24. Heeschen C, Aicher A, Lehmann R, et al. Erythropoietin is a potent physiologic stimulus for endothelial progenitor cell mobilization. Blood 2003;102:1340-6.

25. Szczech LA, Barnhart HX, Inrig JK, et al. Secondary analysis of the CHOIR trial epoetin-alpha dose and achieved hemoglobin outcomes. Kidney Int 2008;74:791-8.

26. Kissel CK, Lehmann R, Assmus B, et al. Selective functional exhaustion of hematopoietic progenitor cells in the bone marrow of patients with postinfarction heart failure. J Am Coll Cardiol 2007;49:2341-9.

27. George J, Shmilovich $\mathrm{H}$, Deutsch V, et al. Comparative analysis of methods for assessment of circulating endothelial progenitor cells. Tissue Eng 2006:12:331-5.

28. Haller $\mathbf{H}$, de Groot K, Bahlmann F, et al. Stem cells and progenitor cells in renal disease. Kidney Int 2005;68:1932-6.

29. Aicher A, Heeschen C, Mildner-Rihm C, et al. Essential role of endothelial nitric oxide synthase for mobilization of stem and progenitor cells. Nat Med 2003:9:1370-6.

30. Ozuyaman B, Ebner $P$, Niesler $U$, et al. Nitric oxide differentially regulates proliferation and mobilization of endothelial progenitor cells but not of hematopoietic stem cells. Thromb Haemost 2005;94:770-2.

31. Peichev M, Naiyer AJ, Pereira D, et al. Expression of VEGFR-2 and AC133 by circulating human $\mathrm{CD} 34(+)$ cells identifies a population of functional endothelial precursors. Blood 2000;95:952-8.

32. Krenning G, Dankers PY, Drouven JW, et al. Endothelial progenitor cell dysfunction in patients with progressive chronic kidney disease. Am J Physiol Renal Physiol 2009:296:F1314-22.

33. de Groot K, Bahlmann FH, Sowa J, et al. Uremia causes endothelial progenitor cell deficiency. Kidney Int 2004;66:641-6. 